\title{
Implementation Fuzzy Weighted Product Preparation Post Disaster Reconstruction And Rehabilitation Action Based Dynamics Decision Support System
}

\author{
Agung Teguh Wibowo Almais ${ }^{1}$, Fatchurrohman ${ }^{2}$, Khadijah Fahmi Hayati Holle ${ }^{3}$, \\ Kurnia Siwi Kinasih ${ }^{4}$, Dyah Ayu Wiranti ${ }^{5}$, and Septian Yustina Yasin ${ }^{6}$ \\ Informatics Engineering State Islamic University Maulana Malik Ibrahim Malang, Indonesia \\ \{agung.twa, fatchur, khadijah.holle\}@ti.uin-malang.ac.id, \\ \{kurniasiwi1,adyah178, septian.yustinayasin1999\}@gmail.com
}

Keywords: Decision Support System Dynamic; Fuzzy-Weighted Product; pattern data; test data; Surveyor

Abstract: The preparation of post-disaster reconstruction rehabilitation action is conducted to determine the level of damage and loss of post-natural disasters that must be handled by the government. In order to prevent the level of post-disaster damage and loss in accordance with the conditions in the field then conducted research implementing Decision Support System Dynamic (DSSD) using the method of Fuzzy-Weighted Product (FWP). The Decision Support System Dynamic (DSSD) is the development of the latest Decision Support System (DSS) model, while Fuzzy is an algorithm for determining the level of importance of each criterion used in the Weighted Product method. Whereas Weighted Product is used as a system pattern data formation. The result is a test of the confusion matrix value of the pattern data calculated using the Fuzzy-Weighted Product (F-WP) method compared to the different test data. The results of the test resulted in three different types of data i.e. the same test data as the pattern data, the test data not the same as the pattern data, and the test data that could not be flown for testing. Each of these types of test data has a percentage of $73 \%$ of the same test data like the pattern data, $22 \%$ of test data is not equal to the pattern data, and $5 \%$ is data that can not be used as test data. From the results of the test can be concluded that the method Fuzzy-Weighted Product (F-WP) can be applied to the Decision Support System Dynamic (DSSD) to assist surveyors in the preparation of the rehabilitation of post-disaster reconstruction action.

\section{INTRODUCTION}

Determination of the level of damage and loss of the post-disaster sector is the action for the preparation of rehabilitation and post-disaster reconstruction. This activity is one of the things that must be done by one of the teams in the Regional Disaster Management Agency (BPBD), which is the planning and Control Team (P3B) to determine the level of loss and damage to the sector Affected by natural disasters, knowing the level of loss and damage will be easy in drafting the rehabilitation action and post-disaster reconstruction to determine the amount of assistance that should be channeled to victims affected by the disaster nature (Almais, Sarosa, \& Muslim, 2016).

In his research (Oetari, JP, \& Nugroho, 2014) explained that to determine the level of damage and damage to the sector due to natural disasters is to use a reference called the Economic Commission for Latin America and the Caribbean (ECLAC). The journal has also been explained that ECLAC has been used by the Indonesian government to calculate losses and damage to earthquakes in Yogyakarta's special region in 2006 and tsunami in special regions of ACEH. At ECLAC there are references to how to determine the level of loss and breakdown of postdisaster sectors. The current Problem is how the ECLAC is applied easily at the time of the surveyors 
at P3B conducted an assessment of the level of loss and damage to the post-disaster sector. Problems can be solved by implementing Information Technology (IT). One of the areas in IT can help the problem is the Decision Support System (DSS). According to (Suryadi \& Ramdhani, 2000) in his book mentioned that to do research on the Decision Support System Many requirements that must be met, including the problems discussed must have a high scientific level and semi Structured.

With the development of the DSS era developed into a dynamic system with the term Decision Support System Dynamic (DSSD). Decision Support System (DSSD) has a difference with the Decision Support System (DSS), which is the Decision Support System (DSS) that does not change the system that is already running when adding criteria and alternatives. With the concept of Decision Support System dynamic (DSSD), the Decision Support System Dynamic (DSSD) is suitable if applied to help the Government (P3B) in conducting the assessment of loss rate and damage to the post-disaster sector due to standard The criteria used to do so will someday increase or less depending on government policy. At this time the standard criteria to conduct an assessment of the level of loss and damage postnatural disasters using standard criteria from the Public Works office on criteria to determine the home or building earthquake resistant natural disasters. These criteria are 1). State of Building 2). State of the building structure 3). The physical state of the building is damaged by 4). Building function 5). Other supporting conditions (Almais, Sarosa, \& Muslim, 2016).

These criteria can be used to build a Decision Support System Dynamic (DSSD) because one of the requirements for building a Decision Support System (DSS) is to have an alternative, criteria, and level of importance. These criteria have a level of interest each depending on the type of cautiousness. In previous research (Suhada, Hidayatulloh, \& Fatimah, 2018) explained that the Fuzzy-Weighted Product method is used as the Decision Support System (DSS) Determination of the customer in obtaining credit in a BPR. The Fuzzy in the journal is used as a level of importance (weight) of each criterion converted to a crisp number. Because the criteria used have different levels of importance depending on the type of criticism, the level of importance can be converted to a crisp number using the Fuzzy method (Kusumadewi, Hartati, Harjoko, \& Wardoyo, 2006). Based on the research, it applied the fuzzy-weighted product method to determine the level of loss and damage to the old post-disaster sector that will be used as a rehabilitation and reconstruction action of post-disaster.

The fuzzy result is used as a scale for the Weighted Product (WP) method in order that each criterion has its own scaling scale depending on the criteria. Then the result of the WP method will be saved to make the system data pattern to become a reference surveyor in determining the damage and loss of the post-disaster sector. To test the accuracy level of the Decision Support System Dynamic (DSSD) system, you can use the method of Confusion matrix in which there is recall, precision, f-measure, and accuracy.

\section{STATE OF THE ART}

In the journal (Suhada, Hidayatulloh, \& Fatimah, 2018) The fuzzy use of the weighted product method is found at the level of importance (weight) of each criterion using crisp numbers resulting from the conversion of fuzzy numbers. The result of the fuzzy number conversion is crisp numbers using reasoning theory where numbers close to number 1 , the higher the dependency rate.

According to (Kusumadewi, Hartati, Harjoko, \& Wardoyo, 2006) method, the weighted Product is the classic formula of the Multi-Criteria Decision Making method. To develop these methods need to be developed with the addition of a fuzzy method so that the Multi-Criteria Decision Making (Weighted Product) method can distinguish the use of the assessment scale of each criterion that corresponds to each criterion.

Weighted Product is one of the solution models on the problem FMADM (Fuzzy Multi-Attribute Decision Making), this method evaluates several alternatives to a set of criteria whereby each criterion interdependent one with Others (Suhada, Hidayatulloh, \& Fatimah, 2018).

Weighted Product method requires normalization process because this method multiplies the judgment result of each criterion, the multiplication result is not meaningful if not compared (divided) with the default value. The importance of the criteria serves as a positive rank in the multiplication process, while the cost weight serves as a negative rank (Suhada, Hidayatulloh, \& Fatimah, 2018).

1) Advantages and disadvantages Weighted Product like an analytical method, Weighted product also has an advantage in the analysis system that can provide value of cost and benefit to the value of each. But having weaknesses is only used in the process of values that have a range value. 
2) Stages Weighted Product

The stages in the calculation of the weighted product method include a) multiplying the entire attribute for all alternatives with weights as a positive rank for the cost attribute. b) The multiplication result is sum to generate value on each alternative. c) Divide the value of $\mathrm{V}$ for each alternate with value on each alternate. $d$ ) found the best alternative sequence that will be the decision of the calculation of vector $\mathrm{V}$ then carried out the alignment sorted from vector value $\mathrm{V}$ of the largest value to the smallest and the largest vector value $\mathrm{V}(\mathrm{Vi})$ is the alternative Ai Elected to the best. Preference for $\mathrm{Ai}$ alternatives using equations (1):

$$
S_{i}=\prod_{j=1}^{n} x_{i j}^{w j}
$$

While the $\sum \mathrm{WJ}=1$ and $\mathrm{WJ}$ is a positive value to the cost attribute. The relative presentation of each alternative uses the following equation (2) (Noviansyah, 2014):

$$
V_{i}=\frac{\prod_{j=1}^{n} x_{i j}^{w j}}{\prod_{j}^{i}\left(X_{j^{*}}\right)}
$$
rank for the attribute of profit and negative value

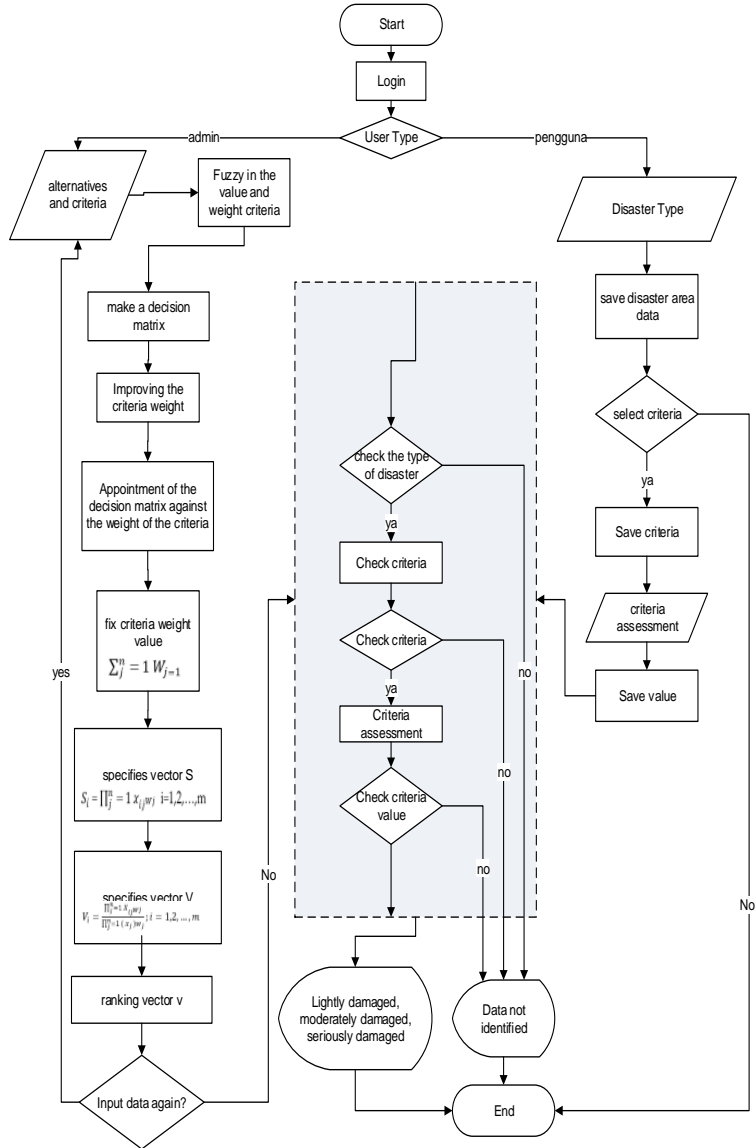

Figure 1. System flows

\section{RESULTS AND DISCUSSION}

pattern data and test data. Pattern data is used to form a data pattern using the Fuzzy-Weighted Product (FWP) method, while test data is used to test built-in pattern data. The pattern data is the result of the breakdown of Fuzzy-Weighted Product (F-WP), using the damage and loss data of the East Java provincial disaster in 2010-2013. The result of the pattern data is a result of the damage and loss of each sector (damaged, mild, moderate and severely damaged).

The result of the pattern data will be tested using damage and loss data after the East Java provincial disaster in 2018. For test data only use the criteria and assessment of each criterion to get the result of the type of damage and loss of each sector (damaged light, moderate damage, and severely damaged). The result of the test data will be searched in the pattern data already created. For more details on how to find or match test data with existing pattern data in the system, see the following figure 1 :

\subsection{RESULT \\ 4.1.1 Modeling Systems}

The Model weighted product uses multiplication to meet the rating of the criteria, where the rating of each criterion should be attached to the corresponding weights. This process is similar to the normalization process, in this case, the weighted product method is used to determine the level of loss and damage of sectors affected by natural disasters. The result of a weighted product method will be stored in a data store for use as pattern data.

The first phase of the admin to input cases using existing criteria is the building state, the state of the building structure, the physical state of the building is damaged, building functions, and other supporting conditions. The second stage gives a level of importance to each of these criteria.

The third stage gives each of these criteria based on the alternatives that are lightly damaged, medium 
damaged, and heavily damaged. The fourth stage of the Decision Support System Dynamic (DSSD) will automatically process the case and will result in a number of alternatives. The fifth stage tests the resultant from step four above with data that has the same characteristics. The sixth stage gets the result that is wanted by the user (surveyor).

\subsubsection{The system needs analysis.}

The need for information on the Decision Support System Dynamic (DSSD) in preparation for rehabilitation and reconstruction action is: the state of the building $(\mathrm{C} 1)$, the state of the building structure (C2), the physical state of the building is damaged (C3), the function of the building (C3), and Other supporting conditions (C4).

From each of these criteria, determined the weight. This weight is then used for the calculation of the Weighted Product (WP) model. The weight used is a Fuzzy number that can be converted to a crisp number. The determination of the number is crisp using reasoning theory where numbers close to 1 , the higher the dependency rate. Conversely, if the number approaches 0 , the dependency rate is getting lower.

There are five criteria used to determine the level of damage and damage to the post-natural disaster sector according to the journal (Almais, Sarosa, \& Muslim, 2016) namely:

Table 1 Data criteria

\begin{tabular}{|r|l|}
\hline \multicolumn{1}{|c|}{ No } & \multicolumn{1}{|c|}{ Criteria Name } \\
\hline 1 & Building conditions \\
\hline 2 & State of the building structure \\
\hline 3 & The physical condition of buildings damaged \\
\hline 4 & Building functions \\
\hline 5 & Other supporting conditions \\
\hline
\end{tabular}

Each criterion in table 1 above has its own scale. By using the fuzzy then the scale of each criterion can be determined by converting the existing fuzzy number to crisp numbers on each criterion in table 1 above.

a. Building state assessment Scale

For the criteria of the state of the building has three types of valuation scale is still standing, tilt and collapse Total. Each scale of the assessment limit has its own value. To scale the rating still stand has a value of $0-0.33$, for the tilt Rating scale has a value of $0.33-0.66$ and for a Total Robot rating scale has a value of $0.66-1$. More details can be seen in Figure 2 below.

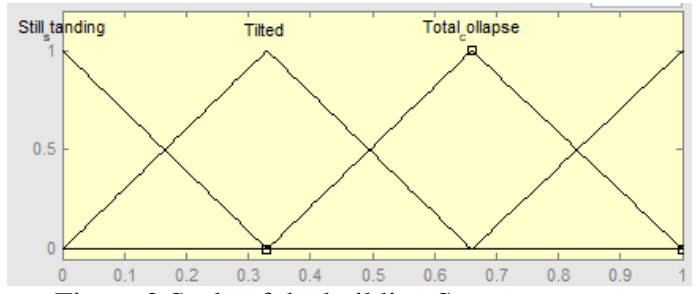

Figure 2 Scale of the building State assessment

b. Building structure State Assessment scale

For the criteria of the state of the building, structure has three types of valuation scale IE small partly damaged light, partly damaged and most damaged. Each scale of the assessment limit has its own value. To scale a small portion of the light damaged assessment has a value of $0-0.33$, for the scale of the scoring the damaged part has a value of $0.33-0.66$ and for the scale of the assessment most damage has a value of $0.66-1$. More details can be seen in Figure 3 below.

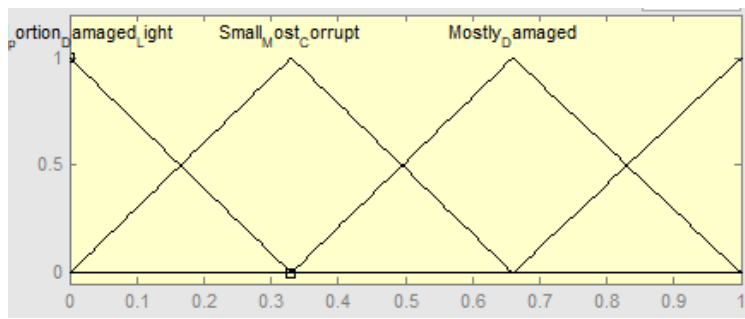

Figure 3 of the building structure State assessment scale

c. The large scale of damaged building conditions

The criteria of the big damaged building conditions have three types of assessment scale is < $30 \%, 30-50 \%$, and $>50 \%$. Each scale of the assessment limit has its own value. To scale the assessment of the $<30 \%$ has a value of $0-0.33$, for a rating scale of $30-50 \%$ has a value of $0.33-0.66$ and for the rating scale $>50 \%$ has a value of $0.66-1$. More details can be seen in Figure 4 below.

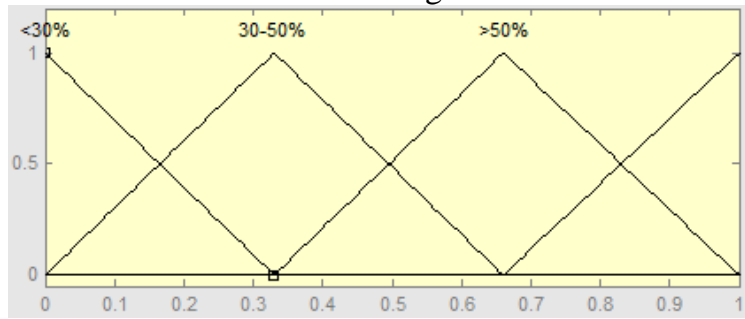

Figure 4 Scale assessment of large damaged building conditions

d. Building function Valuation Scale

For the criteria, building function has three types of assessment scale is harmless, relatively dangerous and harmful. Each scale of the assessment limit has 
its own value. The scale of the harmless rating has a value of $0-0.33$, for the relative hazard rating scale has a value of $0.33-0.66$, and for the scale of hazardous assessments has a value of $0.66-1$. More details can be seen in Figure 5 below.

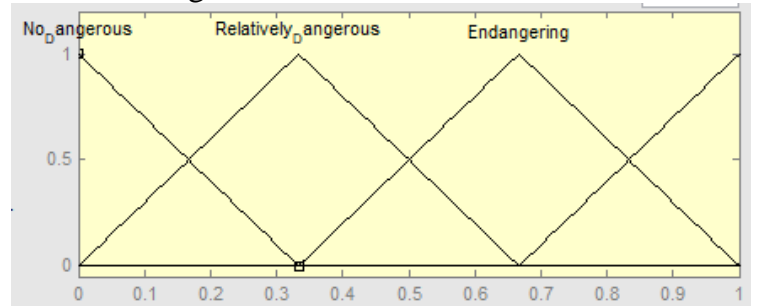

Figure 5 of the building function rating Scale

e. Other supporting state assessment scales

For the criteria of the large damaged building conditions have three types of grading scales that are partially damaged, mostly damaged and damaged in Total. Each scale of the assessment limit has its own value. For the assessment scale, the damaged part has a value of 0-0.33; for the scale of the assessment, most damage has a value of $0.33-0.66$, and for the scale of Total damage assessment has a value of $0.66-1$. More details can be seen in Figure 6 below.

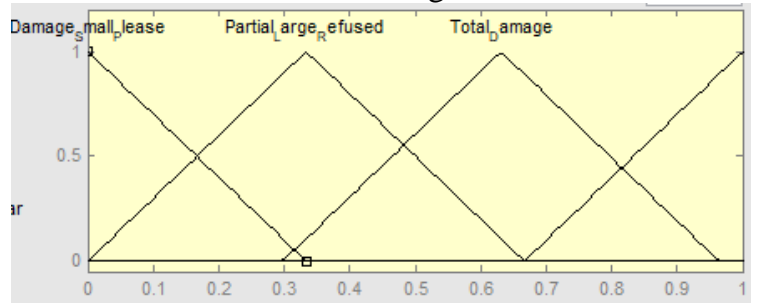

Figure 6 Other supporting conditions assessment scale

The above scale is used to perform assessments and weight for each criterion. If implemented in the form of a system like Figure 7 below:

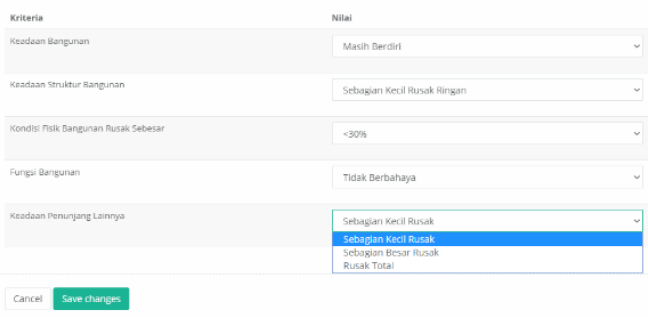

Figure 7 Fuzzy-Weighted Product (F-WP) implementation

\subsection{DISCUSSION}

After the stage of the design entity relational diagram and implementation in programming to create data patterns and test data, then the next step is to test the system using the calculation of the confusion matrix.

\subsubsection{Testing Fuzzy-Weighted Product (F-WP)}

The formation of data patterns on the Decision Support System (DSS) uses the Fuzzy-Weighted Product (F-WP) method. The pattern data will be tested using test data to test the role in the pattern data. Test pattern data will be done three times the experiment with the test data type used the same but different content from the data. Table 2 is a description of the data composition used for pattern data and test data. The test data used is the data on the damage after the East Java provincial disaster in 2010. While the pattern data uses post-disaster data in East Java province 2010-2019.

\begin{tabular}{|c|c|c|c|c|}
\hline \multirow[t]{3}{*}{ Method } & Pattern Data & \multicolumn{3}{|c|}{ Test Data } \\
\hline & \multirow{2}{*}{$\begin{array}{l}\text { Amount of } \\
\text { Data }\end{array}$} & Case I & Case II & $\begin{array}{l}\text { Case } \\
\text { III }\end{array}$ \\
\hline & & $\begin{array}{l}373 \\
\text { data }\end{array}$ & 77 data & 24 data \\
\hline F-WP & 36 & 146 & 28 & 12 \\
\hline
\end{tabular}

Each trial will result in a rule and calculation of a confusion matrix. From some experiments, there is the same rule, so that if the test data used is always the same then the precision, recall, f-measure, accuracy, and response time values are also the same. It can be seen in the results of $1 \mathrm{st}, 2 \mathrm{nd}$, and $3 \mathrm{rd}$ experiments. The similarity of precision value, recall, f-measure, accuracy, and response time of some experiments is caused because the pattern data used produces the same pattern of rules, and the test data used is also the same. In summary, test results can be seen in table 3 .

Table 3 Test Results Fuzzy-Weighted Product (F-WP) Method

\begin{tabular}{|l|c|c|c|l|}
\hline \multirow{2}{*}{$\begin{array}{l}\text { Testing } \\
\text { method }\end{array}$} & \multicolumn{3}{|c|}{ Trial } & \multirow{2}{*}{ Average } \\
\cline { 2 - 5 } & 1 & 2 & 3 & \\
\hline Precision & $56.50 \%$ & $52.80 \%$ & $50 \%$ & $53.1 \%$ \\
\hline Recall & $50.50 \%$ & $36.30 \%$ & $50 \%$ & $45.6 \%$ \\
\hline Accuracy & $53.30 \%$ & $43.02 \%$ & $50 \%$ & $48.7 \%$ \\
\hline $\begin{array}{l}\text { F- } \\
\text { Measure }\end{array}$ & $39.10 \%$ & $36.30 \%$ & $50 \%$ & $41.8 \%$ \\
\hline $\begin{array}{l}\text { Respon } \\
\text { Time }\end{array}$ & $730 \mathrm{sec}$ & $140 \mathrm{sec}$ & 60 & $310 \mathrm{sec}$ \\
$\mathrm{sec}$ & & & \\
\hline
\end{tabular}

Based on table 3, it is known that the more pattern data used will be more likely to be, the greater the value of precision, recall, f-measure, and accuracy 
generated. With the greater value of precision, recall, f-measure, and accuracy are generated, the method used is better. Therefore, by using the testing in table 3 above, shows the performance of the FuzzyWeighted Product (F-WP) method is good and suitable for determining the damage and loss of postdisaster settlement. To explain the test results of the Fuzzy-Weighted Product (F-WP) method can be seen in Figure 8, it illustrates the percentage results between precision value, recall, F-measure, and accuracy. While in Figure 9 is a graph for the test time response from the Fuzzy-Weighted Product (F-WP) method.

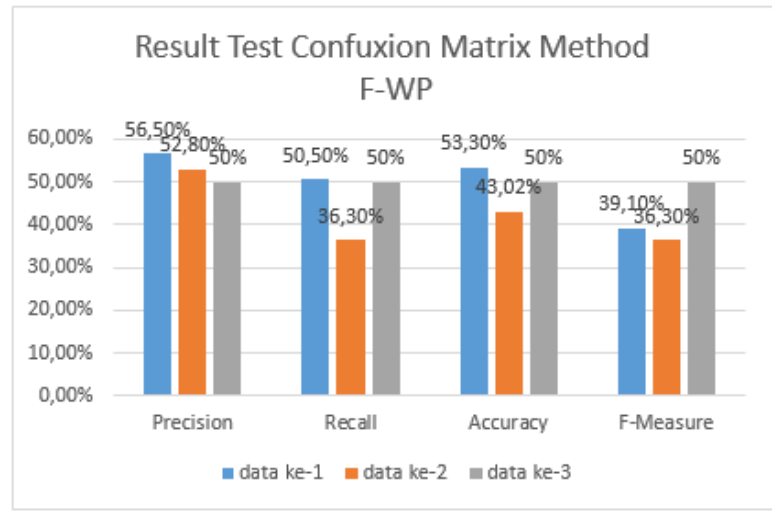

Figure 8 Test Results of The Fuzzy-Weighted Product (F-WP) Method

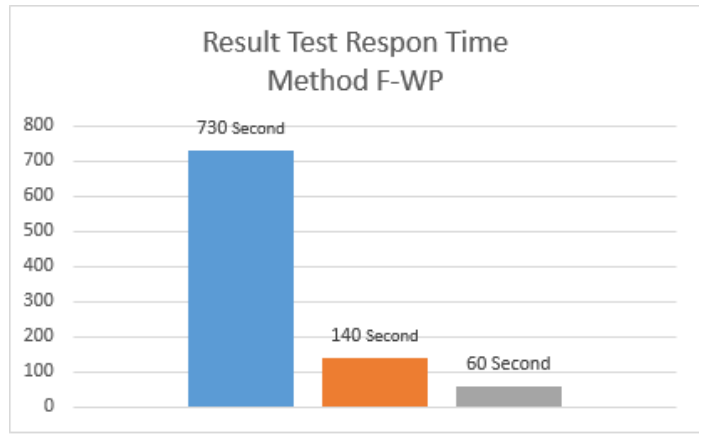

Figure 9 Response Time Test Results of the FuzzyWeighted Product (F-WP) Method

\section{CONCLUSIONS}

Based on the results of the tests that have been done, it can be concluded that the Fuzzy-Weighted Product (F-WP) method can be implemented on the Decision Support System (DSS) to determine the damage and losses of the post-disaster housing well. Since testing the pattern data done using three different test data can result in better data based on precision, recall, f-measure, and accuracy values. But for relaxation time, the method fuzzy-weighted product (F-WP) the more data, the longer because in the method of the fuzzy-weighted product (F-WP), there are measures negation of weights, aggregation of criteria and aggregation of experts. Therefore, the more pattern data used in the Fuzzy-Weighted Product (F-WP) method, The longer the response time as each incoming data will be searched for the negative weight, the critical aggregation, and the Expectation aggregation using the method FuzzyWeighted Product (F-WP). So for further research can use more test data to get better precision, recall, f-measure, and accuracy values. And it can also be developed using the other Fuzzy-Weighted Product (F-WP) methods or Machine Learning methods to get even better relaxation time results.

\section{REFERENCE}

Almais, A. T., Sarosa, M., \& Muslim, M. A. (2016) Implementation Of Multi Expert Multi-Criteria Decision Making Form Rehabilitation and Reconstruction action After a Disaster. MATICS, 27-31.

Kusumadewi, S., Hartati, S., Harjoko, A., \& Wardoyo, R. (2006). Fuzzy Multi-Attribute Decision Making (FUZZY MADM). Yogyakarta: Graha Ilmu.

Noviansyah, D. (2014). Data Mining Concept VS Decision Support System. Yogyakarta: Deepublish.

Oetari, F., JP, S. Y., \& Nugroho, A. (2014). Development of information system for disaster damage and loss assessment using ECLAC (Economic Commission for Latin America and the Caribbean) (case study of Mount Merapi eruption 2010 in Kab. Boyolali. Aiti, 169-183.

Suhada, S., Hidayatulloh, T., \& Fatimah, S. (2018). The application weighs a fuzzy MADM model in a credit-feasibility support decision in BPR, Nusamba Sukaraja (MADHMA's fuzzy application). JUITA, 6(1), 61-71.

Suryadi, K., \& Ramdhani, A. (2000). Decision support System A structural discourse of idealization and implementation of the development concept. Bandung: PT. Remaja. 


\title{
[CONRIST 2019] Information of Publication and Indexation
}

\author{
2 pesan
}

conrist@akakom.ac.id <conrist=akakom.ac.id@edas.info>

Balas Ke: conrist@akakom.ac.id

Kepada: Agung Teguh Wibowo Almais <agung.twa@gmail.com>

Dear Author of CONRIST 2019,

Congratulations! We are pleased to inform you that your paper titled "Implementation Fuzzy Weighted Product Preparation Post Disaster Reconstruction Rehabilitation Action Based Dynamics Decision Support System" has been accepted, after double-blind peer review and oral presentation at the above international conference. Please note the following:

1. Your paper number ID is 1570614242 and please quote this number for all future correspondence. Please check the accuracy of the paper title, address, and spelling of the authors' name and the name of the university. We do not allow any change anywhere after this deadline and nothing can be changed in the draft conference program.

2. Please check whether your EDAS account has been uploaded the e-copyright or not since it is provided from the Scitepress website with your account. The full paper and e-copyright are important to be uploaded and received by the Scitepress. If not, your paper could not be verified and excluded from the next process of publication. Please check that the author list who has uploaded the full paper and copyright via this link: https://edas.info/web/ conrist2019/papercopyright.html

3. Your paper is provisionally accepted for publication by "Scitepress" and the timeline in publishing until indexation by Scitepress publisher as shown below,

a) Date 04-01-2020, reception of all papers and respective copyrights by Scitepress

b) Date 05-01-2020 - 03-02-2020, verifying formatting

c) Date 04-02-2020, production of the proceedings made available in PDF

d) Date 04-03-2020, placement of the proceedings in the Scitepress Digital Library and submission to indexers, including SCOPUS, Thomson Reuters, dblp, Ei Compendex, and Semantic Scholar.

4. Your paper will be included in the international referred Conference Proceedings which will be published online via Scitepress Digital Library website: https://www.scitepress.org which is visited by thousands of readers.

5. Please visit http://conrist.akakom.ac.id and read all the information relating to all other issues. For further corresponding, we will email you.

We hope you can understand. Thank you and please do not hesitate to contact our representative via WhatsApp at 0815-7280-9394 or email conrist@akakom.ac.id with any questions.

With best regards,

\section{CONRIST Admin}

2019 International Conferences on Information System and Technology (CONRIST 2019)

url: http://conrist.akakom.ac.id/

STMIK AKAKOM Yogyakarta

Address : Jl. Raya Janti Karang Jambe No. 143. Yogyakarta 55198, Indonesia

Phone : +62 274486664

E-mail: conrist@akakom.ac.id

For Fast Response :

Mr. Ade

Phone/WA : +62 815-7280-9394 
Congratulations! We are pleased to inform you that your paper titled "Implementation Fuzzy Weighted Product Preparation Post Disaster Reconstruction Rehabilitation Action Based Dynamics Decision Support System" has been accepted, after double-blind peer review and oral presentation at the above international conference. Please note the following:

1. Your paper number ID is 1570614242 and please quote this number for all future correspondence. Please check the accuracy of the paper title, address, and spelling of the authors' name and the name of the university. We do not allow any change anywhere after this deadline and nothing can be changed in the draft conference program.

2. Please check whether your EDAS account has been uploaded the e-copyright or not since it is provided from the Scitepress website with your account. The full paper and e-copyright are important to be uploaded and received by the Scitepress. If not, your paper could not be verified and excluded from the next process of publication. Please check that the author list who has uploaded the full paper and copyright via this link: https://edas.info/web/ conrist2019/papercopyright.html

3. Your paper is provisionally accepted for publication by "Scitepress" and the timeline in publishing until indexation by Scitepress publisher as shown below,

a) Date 04-01-2020, reception of all papers and respective copyrights by Scitepress

b) Date 05-01-2020 - 03-02-2020, verifying formatting

c) Date 04-02-2020, production of the proceedings made available in PDF

d) Date 04-03-2020, placement of the proceedings in the Scitepress Digital Library and submission to indexers, including SCOPUS, Thomson Reuters, dblp, Ei Compendex, and Semantic Scholar.

4. Your paper will be included in the international referred Conference Proceedings which will be published online via Scitepress Digital Library website: https://www.scitepress.org which is visited by thousands of readers.

5. Please visit http://conrist.akakom.ac.id and read all the information relating to all other issues. For further corresponding, we will email you.

We hope you can understand. Thank you and please do not hesitate to contact our representative via WhatsApp at 0815-7280-9394 or email conrist@akakom.ac.id with any questions.

With best regards,

\section{CONRIST Admin}

2019 International Conferences on Information System and Technology (CONRIST 2019)

url: http://conrist.akakom.ac.id/

STMIK AKAKOM Yogyakarta

Address : Jl. Raya Janti Karang Jambe No. 143. Yogyakarta 55198, Indonesia

Phone : +62 274486664

E-mail: conrist@akakom.ac.id

For Fast Response :

Mr. Ade

Phone/WA : +62 815-7280-9394 


\title{
[CONRIST 2019] Your paper \#1570614242 ('Implementation Fuzzy Weighted Product Preparation Post Disaster Reconstruction Rehabilitation Action Based Dynamics Decision Support System')
}

\author{
1 pesan
}

conrist@akakom.ac.id <conrist=akakom.ac.id@edas.info>

Balas Ke: conrist@akakom.ac.id

Kepada: Agung Teguh Wibowo Almais <agung.twa@gmail.com>, Fatchurrohman Fatchurrohman

<fatchurrohman@ayotryout.id>, Khadijah Fahmi Hayati Holle <khadijah.holle@gmail.com>, Kurnia Siwi Kinasih

<kurniasiwi1@gmail.com>, Dyah Ayu Wiranti <adyah178@gmail.com>, Septian Yustina Yasin

<septian.yustinayasin1999@gmail.com>

\section{Dear Mr. ,}

After a rigorous review, with pleasure we would like to inform you that your paper with ID/Tittle: \#1570614242 ('Implementation Fuzzy Weighted Product Preparation Post Disaster Reconstruction Rehabilitation Action Based Dynamics Decision Support System') for CONRIST 2019 has been accepted to be presented and published in The 2019 International Conference on Information Systems and Technologies - CONRIST 2019 which will be held in Yogyakarta, Indonesia during 5-6 November 2019.

The blind review process has already taken from three reviewers and the result attached to this email. You have to revise your paper aligned with the review results.

The reviews are below or can be found at https://edas.info/showPaper.php?m=1570614242.

Please take some steps below.

1. Please register and make a payment to the conference through EDAS system.

2. Please download the Camera Ready of SCITEPRESS Full Paper A4 Template from the website of https://conrist.akakom.ac.id/SCITEPRESS_Conference_MSWord.zip

3. Send the revised full paper in SCITEPRESS format.

4. Please provide Plagiarism Checker. Please be aware, according to the regulation the maximum similarity score has to be less than $30 \%$.

5. Prepare and upload your presentation file in EDAS system.

Moreover, if you are from foreign countries, we would like to inform the best way to travel to Yogyakarta. You can take a flight through Jakarta, Indonesia using international flight and travel from Jakarta to Yogyakarta using domestic flight. you can get into the GRAND ZURI MALIOBORO HOTEL by using Taxi. If you come from any ASEAN countries there are available some low fare flight directly to Yogyakarta.

Please email us if you have any questions related to CONRIST 2019.

\section{Review 1}

Technical content and scientific rigour: Rate the technical content of the paper. (e.g. completeness of the analysis or simulation study, thoroughness of the treatise, accuracy of the models, etc), its soundness and scientific rigour.

Average (3)

Novelty and originality: Rate the novelty and originality of the ideas or results presented in the paper.

Average (3)

Quality of presentation: Rate the paper organization, the clearness of text and figures, the completeness and accuracy of references

Average (3)

Relevance and timeliness: Rate the importance and timeliness of the topic addressed in the paper within its area of research. 
Average (3)

\section{Recommendation: How do you rate your recommendation?}

Possible Accept. (2)

Detailed comments: Please justify your recommendation and suggest improvements in technical content or presentation.

1. Check the template used for this conference

2. Check the appropriate abbreviation

3. All word/sentences must be in the English language even in the tables or figures, recheck figures, ex. Basis data SPK

4. Number all equations used using the template guide

5. Could the author write the fuzzy diagram not in the tools so it is clear and readable which the fuzzy used

6. Check the grammar errors

7. What is the meaning of alternate Table 1?

8. Check the number of figures

9. Differ between flow chart with data flow in figure 2, it should be a flow chart, not a data flow

10. Focus on the Fuzzy Weighted Product only in the implementation, eliminate the database, ERD, etc. I recommend the author(s) to write another manuscript which focuses on the application and the database. So it can be written in 2 manuscripts.

\section{Review 2}

Technical content and scientific rigour: Rate the technical content of the paper. (e.g. completeness of the analysis or simulation study, thoroughness of the treatise, accuracy of the models, etc), its soundness and scientific rigour.

Average (3)

Novelty and originality: Rate the novelty and originality of the ideas or results presented in the paper.

Average (3)

Quality of presentation: Rate the paper organization, the clearness of text and figures, the completeness and accuracy of references

Average (3)

Relevance and timeliness: Rate the importance and timeliness of the topic addressed in the paper within its area of research.

Average (3)

Recommendation: How do you rate your recommendation?

Possible Accept. (2)

Detailed comments: Please justify your recommendation and suggest improvements in technical content or presentation.

Use the latest references

Kind Regards,

\section{CONRIST Admin}

2019 International Conferences on Information System and Technology (CONRIST 2019)

url: http://conrist.akakom.ac.id/

STMIK AKAKOM Yogyakarta

Address : Jl. Raya Janti Karang Jambe No. 143. Yogyakarta 55198, Indonesia

Phone : +62 274486664

E-mail: conrist@akakom.ac.id

For Fast Response : 
Mr. Ade

Phone/WA : +62 815-7280-9394 